Journal of Extension Education

Vol. 28 No. 3, 2016

DOI:https://doi.org/10.26725/JEE.2016.3.28.5688-5694

\title{
Developing a Scale to Measure the Indigenous Wisdom Orientation of Rice Farmers
}

\author{
K.P. Smitha ${ }^{1}$ and Anil Kumar ${ }^{2}$
}

\begin{abstract}
The traditional rice farmers had adopted various indigenous technologies in rice farming which in due course of time was forgotten after the advent of high yielding varieties that warranted excessive use of chemical inputs. Hence a study was designed to develop a scale to measure the indigenous wisdom orientation of stakeholders in rice farming. The study was conducted in Palakkad district of Kerala. Fifty statements reflecting the indigenous wisdom orientation were generated. Likert's method was employed in the scale construction and the final scale comprising 14 statements was standardized.
\end{abstract}

Keywords : Indigenous wisdom orientation, Scale construction, Likert's method, Item analysis, Reliability, Validity

\section{INTRODUCTION}

Rice is life as it plays an important role in the environment, society, culture, politics, business and above all it is the life saving grain of 3 billon people of this planet. Rice wetland eco-system is very important in maintaining ecological balance. It has relevance in influencing the microclimate of the ecosystem, preventing floods and drought and conserving the floral and faunal diversity. Rice area in India increased from 30.81 Million Hectares in 1950-51 to 43.97 Million Hectares in 2011-12, while the production has scaled greater heights from 20.58 to 104.32 million
MT during the same period (Department of Agriculture and Co-operation, 2013). This increase may be attributed to green revolution, which was a milestone in the agrarian history. Though green revolution contributed significantly in increasing production and productivity in the initial years, the adverse effects visibly stands out as deterioration of soil quality, environmental pollution due to unscientific use of inorganic inputs, loss of biodiversity and genetic erosion.

Rice wetland eco-system being highly fragile, the adverse effects of input intensive farming is prominent and far-reaching. Traditional farmers had

1. Research Assistant, Dept. of Soil Survey \& Soil Conservation, Govt. of Kerala and 2.Dean, College of Agriculture, Kerala Agricultural University, Vellayani, Kerala. 
adopted indigenous technologies, which were mostly on the "Live and Let Live" concept. They used low external input technologies relevant to local resources. Indigenous Technical Knowledge (ITK) is the systematic body of knowledge acquired by local people through the accumulation of experiences, informal experiments and intimate understanding of the environment in a given culture (Rajasekaran, 1993). Most of the indigenous technologies were eco-friendly and expressed high concern for the environment we live in. Environmental concerns of the stakeholders in rice cultivation have a greater voice on the future of sustainable rice farming and traditional farmers with an orientation towards indigenous wisdom were found to express concern for environment.

Indigenous wisdom orientation was defined for the study as the degree to which an individual is oriented towards the knowledge generated over a period of time by the local community through trial and error and/or deliberate experiments in order to meet their needs.

This study was undertaken to develop a scale to measure the indigenous wisdom orientation of farmers in rice farming and to standardize the scale constructed to measure the indigenous wisdom orientation of farmers in rice farming.

\section{METHODOLOGY}

The research was undertaken in the state of Kerala, India, Palakkad district was selected purposively as the district accounts for about $1 / 3^{\text {rd }}$ of the total area under rice cultivation of Kerala state and has all the agro-socio-economic conditions suited for paddy cultivation.

There are 13 block panchayats in Palakkad district. Of these, four predominantly rice growing blocks viz. Kollengode, Kuzhalmannam, Chittur and Alathur were purposively selected with the highest net rice area.

A total of 25 farmer respondents for item analysis and 30 for testing the reliability were selected based on the production of rice in the various blocks. It was ensured that the twenty-five farmers selected for item analysis were removed from their respective lists before the selection of thirty farmers for testing reliability. Thus the total number of farmer respondents selected for the scale construction was 55 .

The relevant items covering the universe of content in the measurement of indigenous wisdom orientation were collected by extensive review of literature and discussion with experts in the concerned field. A total of 50 statements reflecting the indigenous wisdom orientation of the respondents were generated. The statements were then edited using the criteria suggested by (Edwards, 1957) and finally 35 statements were retained after deleting ambiguous, irrelevant and nonconforming statements as per the above said criteria. 
The relevancy of the items generated was established by sending these statements to 50 judges with appropriate instructions. The judges comprised experts in the field from agricultural Universities across South India. The experts were to rate the degree of relevancy of each item in measuring the indigenous wisdom orientation of the stakeholders on a five point continuum as 'Most relevant, 'Relevant', 'Undecided' 'Less relevant' and 'Not relevant' with scores 5, 4, 3, 2 and 1 respectively. Out of the 50 judges, 40 responded within a period of one month. The scores for each of the items were summated over all the respondents and a relevancy index was worked out using the formula:

Relevancy index $=\frac{\text { Total score obtained on each item }}{\text { Maximum possible score }} \times 100$

Those items, which secured a relevancy index of 80 and above, were finally selected, thereby retaining 26 items to be included in the scale. Item analysis was performed for the statements selected and was standardized by testing its validity and reliability. Item analysis is a set of procedures that are applied to know the indices for truthfulness (or validity) of the items in a scale (Singh, 2006). The indices used in the selection of the items for the study are a) Index of Discrimination ('t'-test), suggested by Edwards and b) Item score - Total score correlation (Pearson's 'r'), suggested by Anastasi (1961) and Guilford (1971). The 26 items selected based on the relevancy rating by the judges were administered to 25 farmer respondents and the responses were obtained on a five - point continuum ('Strongly agree', 'Agree', 'Undecided', 'Disagree' and 'Strongly disagree'). For carrying out item analysis, two types of scores were used. These were the item score, referring to the score of an individual on a particular item and the total score referring to the summation of the item scores of an individual. These scores were used to arrive at the discrimination index and the item score total score correlation. The index of discrimination indicates the power of an item to discriminate the low effectiveness category from the high effectiveness category of the respondents. Following the suggestion of Edwards (1957), 25\% of the subjects with the highest total score and $25 \%$ of the subjects with the lowest total score were selected. The critical ratio (t-value) of each item was calculated using the formula: -

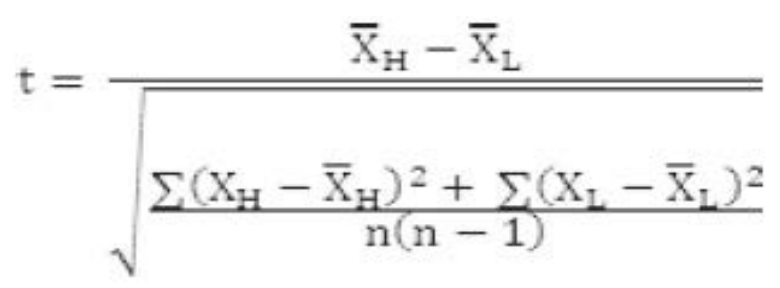

Where,

$\mathrm{X}_{\mathrm{H}}=\quad$ Mean of the score of an item for the high group

$\mathrm{X}_{\mathrm{L}}=\quad$ Mean of the score of an item for the low group 
Journal of Extension Education

$\mathrm{n}=$ Number of subjects in a group

In item score-total score correlation the correlation between the individual item score and total score is computed as a measure of the discriminatory power of the item.

The scale developed was standardized by testing its reliability and validity. The reliability of the scale refers to the consistency of the scores obtained by the same individuals on different occasions or with different sets of equivalent forms. Split-half reliability was used in the present study using odd-even method. The scale developed was administered to 30 respondents and their responses were collected. The scores obtained for all the odd items and all the even items were pooled. The two sets of scores thus obtained were correlated using pearson's product moment correlation. The reliability of the full test was obtained using the formula :
Reliability of the full test $=\frac{2 \times \text { Reliability of the } 1 / 2 \text { test }}{1+\text { Reliability of the } 1 / 2 \text { test }}$

A scale is said to be valid when it actually measures, what it tends to measure and the scale was also assessed for its content validity.

\section{FINDINGS AND DISCUSSION}

The results of the study have been presented in this section under the subheads viz. $t$-value and $r$-value of the statements, standardization of the scale and administration of the scale. The discrimination index and the item scoretotal score correlation of the 25 items performed are presented in Table.1. It could be observed that 20 items had discrimination index values above 2.228 and 21 items had significant item score - total score correlation (' $r$ ' value above $0.4)$ considering these two factors, 17 items which had both ' $t$ '-values and ' $r$ 'value high were chosen for the scale.

Table 1.

Item Analysis

\begin{tabular}{|c|l|c|c|}
\hline $\begin{array}{r}\text { S1. } \\
\text { No. }\end{array}$ & \multicolumn{1}{|c|}{ Statements } & $\begin{array}{c}\text { r } \\
\text { value }\end{array}$ & $\begin{array}{c}\text { t } \\
\text { value }\end{array}$ \\
\hline 1. & $\begin{array}{l}\text { Development activities to be participative should consider the } \\
\text { indigenous wisdom of the local people. * }\end{array}$ & 0.937 & 2.445 \\
\hline 2. & Indigenous wisdom mostly fits to the local needs & 0.339 & 1.69 \\
\hline 3. & $\begin{array}{l}\text { Compared to many modern technologies that harms the } \\
\text { environment indigenous practices are mostly sustainable. * }\end{array}$ & 0.844 & 8.062 \\
\hline 4. & $\begin{array}{l}\text { Indigenous knowledge ought to be eradicated as soon as } \\
\text { possible through education and modernization process. * }\end{array}$ & 0.825 & 6.708 \\
\hline
\end{tabular}




\begin{tabular}{|c|c|c|c|}
\hline 5. & $\begin{array}{l}\text { Indigenous wisdom is a resource that local people can use to } \\
\text { further their own development. * }\end{array}$ & 0.656 & 6.761 \\
\hline 6. & $\begin{array}{l}\text { Indigenous wisdom has to be preserved in situ, as they are } \\
\text { foundation to strengthen the existing knowledge. * }\end{array}$ & 0.67 & 4.025 \\
\hline 7. & $\begin{array}{l}\text { We have to recognize indigenous wisdom as an important } \\
\text { national resource. * }\end{array}$ & 0.869 & 8.485 \\
\hline 8. & $\begin{array}{l}\text { Indigenous wisdom has no scientific basis and hence need not } \\
\text { be preserved. * }\end{array}$ & 0.862 & 11.783 \\
\hline 9. & Indigenous practices use less costly external inputs & 0.487 & 2.15 \\
\hline 10. & $\begin{array}{l}\text { Indigenous practices are better as they require less external } \\
\text { inputs. * }\end{array}$ & 0.765 & 3.503 \\
\hline 11. & $\begin{array}{l}\text { Indigenous wisdom can be utilized more effectively for } \\
\text { grassroots participatory development process. * }\end{array}$ & 0.703 & 2.907 \\
\hline 12. & $\begin{array}{l}\text { Indigenous wisdom documentation and compilation ought to } \\
\text { be a research priority of highest order. * }\end{array}$ & 0.624 & 4.781 \\
\hline 13. & $\begin{array}{l}\text { Newer technologies have to be developed considering the } \\
\text { indigenous practices of the locality. * }\end{array}$ & 0.816 & 7.319 \\
\hline 14. & $\begin{array}{l}\text { Traditional methods of farming has to be neglected in order to } \\
\text { raise the living of farmers }\end{array}$ & 0.325 & 1.928 \\
\hline 15. & $\begin{array}{l}\text { Modern technologies should judiciously make use of indigenous } \\
\text { knowledge base for designing and developing effective } \\
\text { technologies. * }\end{array}$ & 0.959 & 4.568 \\
\hline 16 & $\begin{array}{l}\text { Indigenous wisdom is not important, as it does not cover the } \\
\text { management of natural environment. }\end{array}$ & 0.738 & 11.000 \\
\hline 17. & $\begin{array}{l}\text { Indigenous wisdom is very important, as they are cumulative, } \\
\text { representing generations of experiences. * }\end{array}$ & 0.819 & 7.906 \\
\hline 18. & $\begin{array}{l}\text { Indigenous knowledge systems are highly reliable as they are } \\
\text { the result of careful observation and trial and error experiments. }\end{array}$ & 0.447 & 1.928 \\
\hline
\end{tabular}




\begin{tabular}{|c|l|l|l|}
\hline 19. & $\begin{array}{l}\text { Indigenous knowledge systems are static with no new knowledge } \\
\text { added to it. }\end{array}$ & 0.301 & 2.236 \\
\hline 20. & $\begin{array}{l}\text { Introduction of market-oriented agricultural and forestry } \\
\text { practices had no effect on indigenous wisdom. }\end{array}$ & 0 & 1.348 \\
\hline 21. & Research on indigenous wisdom need not be gender sensitive. * & 0.91 & 2.907 \\
\hline 22. & $\begin{array}{l}\text { Indigenous knowledge systems minimize disruption of existing } \\
\text { practices compared to modern technologies. }\end{array}$ & 0.641 & 2.236 \\
\hline 23. & $\begin{array}{l}\text { Indigenous wisdom ought to be conserved as it integrates } \\
\text { culture and religion.* }\end{array}$ & 0.843 & 5.814 \\
\hline 24. & $\begin{array}{l}\text { Indigenous knowledge systems minimize risk rather than } \\
\text { maximize profit. }\end{array}$ & 0.325 & 1.039 \\
\hline 25. & $\begin{array}{l}\text { Unique and promising technologies have to be patented by the } \\
\text { communities that have generated it. * }\end{array}$ & 0.753 & 4.385 \\
\hline 26. & $\begin{array}{l}\text { The younger generation has to be made aware about the value } \\
\text { of indigenous wisdom. * }\end{array}$ & 0.752 & 6.581 \\
\hline
\end{tabular}

* Statements selected to construct the final scale.

\section{Standardization of the Scale}

A scale should measure what it intends to measure and it should be consistent in its measurement. A scale thus has to be standardized before it is administered. The present scale developed was also standardized by verifying its reliability and validity.

\section{Reliability of the Scale}

The correlation co -efficient $(\mathrm{r}$ $=0.632$ ) for the half test was obtained. The reliability of the full test was found to be 0.774 , which indicates appreciable reliability of the scale.

\section{Validity of the Scale}

Determination of content validity essentially involves the systematic examination of the test content to determine whether it covers a representative sample of the behavior domain being measured. Care was taken to include the important items covering the universe of content with respect to the indigenous wisdom orientation of farmers thereby satisfying the content validity criterion. 


\section{Administration of the Scale}

The final scale consisting of 17 statements in random order can be presented to respondents to indicate their responses on a five point scale consisting of Strongly Agree, Agree, Undecided, Disagree, Strongly with scores 5,4,3,2 and 1 respectively for positive statements and the reverse scores for negative statements. The total score for all the statements of each respondent can be worked out and categorized into 'high', 'medium' and 'low' orientation to indigenous wisdom based on the obtained scores.

\section{CONCLUSION}

A scale was developed and standardized to measure the indigenous wisdom orientation of farmers. It was found to be reliable and valid. The scale developed to measure the indigenous wisdom orientation of farmers in rice farming is not specific for use with any particular category of respondents. The scale is not location specific and can be used in any geographical area with slight modification. It can also be effectively used among respondents involved in growing other crops. The scale developed to measure the indigenous wisdom orientation of rice farmers would serve to quantify the orientation level of farmers towards indigenous wisdom and the data so obtained could be replicated elsewhere to understand the indigenous wisdom orientation of the people, which in turn will help in formulating strategies for encouraging conservation/sustainable farming.

\section{REFERENCES}

Anastasi, A. (1961). Psychological Testing. New York: The McMillan Co.

Department of Agriculture and Cooperation. (2013). Agricultural Statistics at a glance. Retrieved from http://eands.dacnet.nic.in/.

Edwards, A .L. (1957). Techniques of Attitude Scale Construction. New York: Appleton Century Crofts Inc.,

Guilford, J. P. (1971). Psychometric Methods. New Delhi: Tata McGraw Hill Publishing Co.

Rajasekaran, B. (1993). Indigenous technical practices in a rice based farming system. Ames: CIKARD

Singh, A.K. (2006). Tests, Measurements and Research Methods in Behavioural Sciences. New Delhi: Bharti Bhawan Publishers and Distributors. 